\title{
CORRELATION BETWEEN ABO BLOOD GROUPS AND MALOCCLUSION IN A SAMPLE OF EGYPTIAN POPULATIONS: A CROSS SECTIONAL STUDY
}

\author{
Adel Rashid * and Hanem El Feky *
}

\begin{abstract}
Background: The authors sought to investigate. the relationship between the blood groups and malocclusion in group from the Egyptian population.

Methods: A total of 300 students (172 females and 128 males) in the age ranges of 17 - 22 years participated in this study. A separate sheet was used as a record for each student providing complete information about their blood group type and malocclusion. The blood group of each student was first determined and then divided into four groups according to their $\mathrm{ABO}$ blood group into $\mathrm{A}, \mathrm{B}$, $\mathrm{O}$ and $\mathrm{AB}$ group. Inside each group we started to diagnose their type of occlusion, the presence or absence of any malocclusion followed by classifying this malocclusion.
\end{abstract}

Results: Using Chi-square $\left(x^{2}\right)$ test with significance level was set at $\mathrm{P} \leq 0.05$, it was found that a correlation exists between the blood group and malocclusion indicating that the prevalence of malocclusions is highest in blood group A followed by $\mathrm{O}$ then $\mathrm{B}$ and the least prevalence in $\mathrm{AB}$.

Conclusions: The estimation of the correlation between blood groups and malocclusions showed that blood groups have an association with malocclusions with highest prevalence in blood group A followed by $\mathrm{O}, \mathrm{B}$ and $\mathrm{AB}$ in group of Egyptian population.

\section{INTRODUCTION}

Epidemiological studies have shown that around $20 \%$ of the world's population suffers from malocclusion and other maxillofacial deformities ${ }^{(1)}$. Types of malocclusion are multifactorial in origin and can be attributed to genetic, hereditary and acquired causes ${ }^{(2)}$.Predicting a genetic pattern within a specific maxillofacial deformity is difficult due to the multi-factorial characteristics of facial development, but epidemiological evaluations can reveal the relationship between such deformities and some genetic characteristics- or accompanied diseases- which will help in recognition and treatment ${ }^{(2,3)}$.

One of the most important human genetic characteristic is the relationship between the 
$\mathrm{ABO}$ blood group and some of those diseases and deformities. The ABO blood group system is the first and the most important system defined in $1901^{(2)}$. There are two main. Antigens: A and B in the ABO system that are either present on cell membranes or secreted into the plasma and other fluids of the body. The presence or absence of these antigens results in the four blood groups: A, B, AB, and $\mathrm{O}$. These antigens are present on the $9^{\text {th }}$ chromosome and are inherited.co-dominantly ${ }^{(3,4)}$.

On evaluating the literature, limited. Studies have been carried out to investigate the association between $\mathrm{ABO}$ blood groups and occurrence of oral diseases. Pinkston and cole ${ }^{(5)}$ found that 38.5 percent of salivary gland tumors in cases with blood group A was similar to the 39.0 percent observed for controls. No differences were observed when benign and malignant tumors were considered separately, nor for any of the major histologic types of tumor. The distribution of Rh factor among cases and control also did not differ significantly.

Mortazavi et al ${ }^{\left({ }^{()}\right)}$, found that People with blood group B are at a greater risk of developing oral cancer, and female patients under 50 years of age with blood group B have the highest risk to develop non-squamous cell oral cancer.

Kaslick et $\boldsymbol{a l}^{(7)}$, studied the association of aggressive periodontitis and $\mathrm{ABO}$ blood group, they found significantly less patients with blood group $\mathrm{O}$ and more patients with blood group $\mathrm{B}$. Roberts ${ }^{(8)}$, discussed the relationship between $\mathrm{ABO}$ blood group and susceptibility to chronic disease as an example of genetic basis for family .predisposition. Koregol $\boldsymbol{e t}_{\boldsymbol{~ a l}} \boldsymbol{l}^{(9)}$, in a study concluded that blood group A formed a significantly higher percentage in the gingivitis group, blood group $\mathrm{O}$ formed a higher Percentage in the periodontitis group and blood group $\mathrm{AB}$ showed the least percentage of periodontal diseases.

Vivek et al ${ }^{(10)}$ found that subjects with blood group $\mathrm{O}$ and $\mathrm{Rh}$ positive had a greater propensity. for periodontitis. Gheisari et $\boldsymbol{a l}^{(1)}$, in their study showed that among different blood Groups; those with blood group B were found to have a greater likelihood of association with maxillofacial deformities and the Probability of the association of such. Deformities was found to be the least with blood group A.

On the other hand, only few studies investigated the relationship between $\mathrm{ABO}$ blood groups and the incidence of malocclusion ${ }^{(11-16)}$. For this reason, this study was conducted to investigate if there is a relationship between $\mathrm{ABO}$ blood group and the dental malocclusions in a group from the Egyptian population.

\section{MATERIALS AND METHODS}

\section{Subjects:}

Three hundreds of students (172 females and 128 males) at the faculty of Dentistry, Fayoum University. Their age ranges from 17-22 years. A separate sheet was used as a record for each individual including name of the student, age, sex, graduation level, identification number, blood group, and the malocclusion. While the exclusion criteria were: the presence of any systemic disease, craniofacial anomaly, previously orthodontic treatment, extracted teeth, congenitally missed teeth and retained deciduous teeth.

Sample size calculation was based upon the results of Gupta SP (2018) ${ }^{(17)}$. Using alpha $(\alpha)$ level of $(5 \%)$ and $(\beta)$ level of $20 \%$ i.e. Power $=80 \%$. Calculation yielded a minimum of 68 Class I cases, 33 Class II cases and 32 Class III cases giving a total of 134 malocclusion cases. Sample size calculation was performed using $\mathrm{G}^{*}$ Power Version 3 1.9.2

The blood group of each student was first determined at the biochemistry Department, faculty of Medicine, Fayoum University then they were divided into four groups according to their $\mathrm{ABO}$ blood group into A, B, O and AB group. Inside each 
group we started to diagnose their type of occlusion, the presence or absence of any malocclusion followed by classifying this malocclusion.

\section{Methods of blood testing:}

\section{B.1. Principle of blood grouping}

Immunology is usually defined as the study of resistance to infectious disease; its subdivision, serology, is the study of antisera, or more properly, the study of the anti-bodies elicited by the antigen of infectious disease process producing an antigenantibody reaction. The red blood corpuscles of man may contain two distinct antigens, and the letters A and $\mathrm{B}$ were chosen to represent them Persons with type 0 blood possess neither of these antigens, and type $A B$ persons possess both the reciprocal antibody is found in the plasma ${ }^{(8 \& 9)}$.

To determine the blood group of a person, his/ her red cells are made to react with commercially available anti-serum containing known agglutinins. The slide is then examined by the naked eye.to detect the presence. or absence of clumping and hemolysis (agglutination) of red cells, which occurs as a result of antigen-antibody reaction ${ }^{(10 \& 11)}$.

\section{B.2. procedure of blood testing}

A dry microscope slide was divided into two proportions. The right half of the slide was marked anti-A (antisera A or alpha agglutinins) and the left half of the slide was marked anti-B (antisera B or beta agglutinins). Another slide was marked $\mathrm{S}$ for only red cell suspension in saline. No antiserum will be added to this. Then a finger-prick was done under aseptic conditions, and two drops of blood were added to the saline on the slide and mixed with toothpick and thus red cell suspension was prepared for each subject assigned in this study. ${ }^{(12,13)}$

One drop of antisera A and B was placed on the right and left halves of the slide. The antisera and red cell suspension were mixed with the help of two separate tooth picks and waited for 8-10 min. Then the two antisera - red cell mixtures on the slide were inspected, first with the naked eye to see whether agglutination (clumping or hemolysis) had taken place or not. It appeared as a coarse separation of red cells in isolated clumps (red precipitates of cells) and this agglutination was confirmed under low magnification microscope. ${ }^{(14,15)}$

Thus, the presence or absence of agglutination indicated individual's blood group (blood. type) as shown in Table (I).

\section{Diagnosis and classification of malocclusion}

The normal occlusion group inside each blood group showed bilateral Angles Class I molar relationship with acceptable overjet and overbite and well-aligned arches. While, the malocclusion group fulfilled the criteria according to Angles classification of malocclusion i.e. Class I, Class II and Class III malocclusions.

Class I Malocclusion group showed bilateral Angles Class I molar relationship with one or more. of these characteristics: Crowded anteriors, spacing, protruded maxillary incisors, unilateral or bilateral posterior cross bite, anterior or posterior open bite, deep.anterior overbite.

Class II Malocclusion group showed bilateral Angles Class II molar relationship with proclined. maxillary incisors and increased overjet (Angles Class II div 1 malocclusion) or with retroclined maxillary central incisors and proclined lateral. incisors (Angles Class II div 2 malocclusion).

Class III .Malocclusion group showed bilateral. Angles Class III molar relationship with end to end incisor relationship incisors or in cross bite relationship.

\section{Statistical analysis:}

Qualitative data were presented as frequencies and percentages. Chi-square $\left(x^{2}\right)$ test was used for comparisons related to qualitative data. 
The significance level was set at $\mathrm{P} \leq 0.05$. Statistical analysis was performed with IBM ${ }^{\circledR}$ SPSS $^{\circledR}$ Statistics Version 20 for Windows.

\section{RESULTS}

\section{1- The distribution frequency of $\mathrm{ABO}$ blood groups in the sample:}

The distribution of blood groups is presented in Figure (1). The most prevalent blood group was blood group $(\mathrm{O})$ in 113/332 subjects (34\%) followed by blood group (A) in 107/332 subjects (32.3\%) then blood group (AB) in 58/332 subjects (17.5\%). The least prevalent blood group was (B) in 54/332 subjects $(16.3 \%)$.

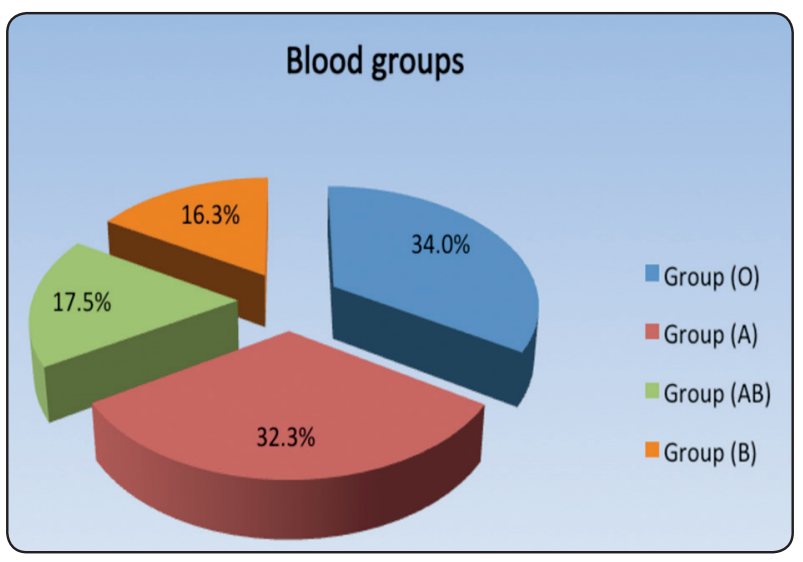

Fig. (1): Pie chart representing distribution of blood groups in the study sample

\section{2- The correlation between the blood groups and malocclusion :}

There was a highly statistical significant correlation between the blood groups and malocclusion indicating that the prevalence of malocclusions is highest in blood group A followed by $\mathrm{O}$ then $\mathrm{B}$ and the least prevalence in blood group $\mathrm{AB}$ as presented in table (II) and figure (2).
TABLE (II): Frequencies, percentages and results of Chi-square test for the comparison between blood groups in subjects with normal occlusion and malocclusion :

\begin{tabular}{|c|c|c|c|c|c|}
\hline \multirow{2}{*}{$\begin{array}{l}\text { Blood } \\
\text { group }\end{array}$} & \multicolumn{2}{|c|}{$\begin{array}{l}\text { Normal occlusion } \\
\quad(\mathrm{n}=100)\end{array}$} & \multicolumn{2}{|c|}{$\begin{array}{l}\text { Malocclusion } \\
(\mathrm{n}=232)\end{array}$} & \multirow{2}{*}{$P$-value } \\
\hline & $\mathrm{n}$ & $\%$ & $\mathrm{n}$ & $\%$ & \\
\hline A & 30 & 30 & 77 & 33.2 & \multirow{4}{*}{0.127} \\
\hline $\mathrm{AB}$ & 20 & 20 & 38 & 16.4 & \\
\hline B & 10 & 10 & 44 & 19 & \\
\hline $\mathrm{O}$ & 40 & 40 & 73 & 31.5 & \\
\hline
\end{tabular}

*: Significant at $P \leq 0.05$

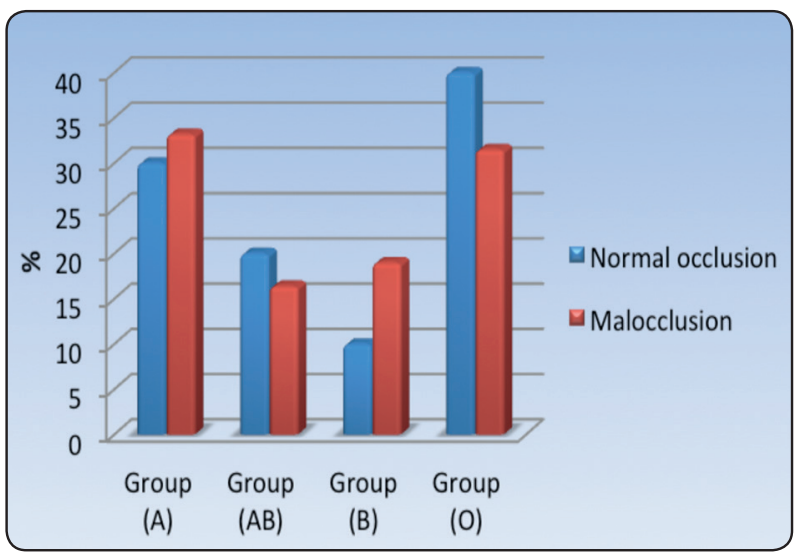

Fig. (2): Distribution of malocclusion and normal occlusion with blood group types.

\section{3- Distributing the different types of malocclu- sion related to each blood group:}

The statistical analysis also revealed that the prevalence of subjects with blood groups $\mathrm{A}, \mathrm{AB}, \mathrm{B}$ and $\mathrm{O}$ were distributed as $32.7,10.9 \%, 15.5 \%$ and $40.9 \%$ respectively among the Class I malocclusion patients while distributed as $35.8 \%, 14.9 \%$, $19.4 \%$ and $29.9 \%$ respectively among the Class II malocclusion and distributed as $30.9 \%, 29.1 \%$, $25.5 \%$ and $14.5 \%$ respectively among the Class III malocclusion as shown in table (III) and figure (3). 
TABLE (III): Frequencies, percentages and results of Chi-square test for the comparison between blood groups in subjects with normal occlusion and different classes of malocclusion :

\begin{tabular}{|c|c|c|c|c|c|c|c|c|c|}
\hline \multirow{2}{*}{$\begin{array}{c}\text { Blood } \\
\text { group }\end{array}$} & \multicolumn{2}{|c|}{$\begin{array}{c}\text { Normal occlusion } \\
(\mathrm{n}=100)\end{array}$} & \multicolumn{2}{c|}{$\begin{array}{c}\text { Class I Malocclusion } \\
(\mathrm{n}=110)\end{array}$} & \multicolumn{2}{c|}{$\begin{array}{c}\text { Class II Malocclusion } \\
(\mathrm{n}=67)\end{array}$} & \multicolumn{2}{c|}{$\begin{array}{c}\text { Class III Malocclusion } \\
(\mathrm{n}=55)\end{array}$} & $\%$ \\
\hline & $\mathrm{n}$ & $\%$ & $\mathrm{n}$ & $\%$ & $\mathrm{n}$ & $\%$ & $\mathrm{n}$ & $\%$ \\
\hline $\mathrm{A}$ & 30 & 30 & 36 & 32.7 & 24 & 35.8 & 17 & 30.9 & 29.1 \\
\hline $\mathrm{AB}$ & 20 & 20 & 12 & 10.9 & 10 & 14.9 & 16 & 25.5 \\
\hline $\mathrm{B}$ & 10 & 10 & 17 & 15.5 & 13 & 19.4 & 14 & 25.007 \\
\hline $\mathrm{O}$ & 40 & 40 & 45 & 40.9 & 20 & 29.9 & 8 & 14.5 & \\
\hline
\end{tabular}

*: Significant at $P \leq 0.05$

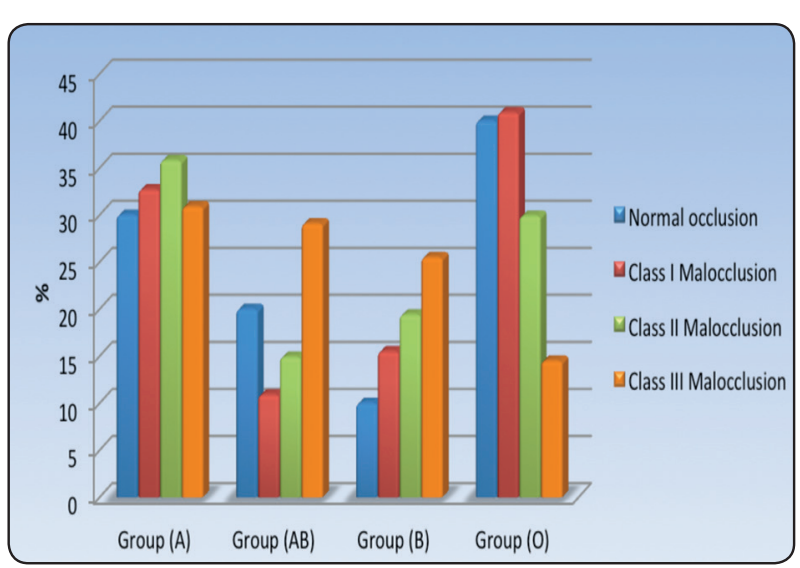

Fig. (3): Bar chart representing blood groups distribution in cases with normal occlusion and cases with different classes of malocclusion

\section{DISCUSSION}

This study was conducted on 300 students at the faculty of Dentistry, Fayoum University. Students had overall good general health to have a proper evaluation and classification, of blood group. As the malocclusion and blood groups both are related to genetic components, it can be hypothesized that blood groups have an association with malocclusions. The aim of this study was to investigate if there is a relation between $\mathrm{ABO}$ blood group and the dental malocclusions.

It was reported that blood group ' $\mathrm{A}$ ' has a wider distribution among Eskimos, 'B' in Chinese and In- dians, the group ' $\mathrm{O}$ ' in Americans, Canadian Indians, Czechoslovakians and Kenyans. ${ }^{(15)}$ In a large country like Egypt; a large variation in prevalence of malocclusion exists. The distribution of $\mathrm{ABO}$ blood groups also varies regionally, and from one population to another. The most common blood group representing this group of the Egyptian population was blood group O (34\%) followed by group A, AB and $\mathrm{B}$ occurred at the lowest frequency $(16.3 \%)$.

In our study, the results revealed that there was a statistically significant correlation $(\mathrm{P} \leq 0.05)$ between malocclusion types and blood grouping system. The results of the current study agreed with the findings of Sharma et $\boldsymbol{a l}^{(\mathbf{1 3 )})}$, and disagreed with that of Mustafa et al ${ }^{(14)}$, Sanjay Prasad Gupta ${ }^{(15)}$ and shokor at al ${ }^{(16)}$ who stated that there was no correlation between them. This disagreement may be due to the geographic, diversity of the population, and racial variation.

The prevalence of malocclusions in the current study was highest in blood group A (33.2\%) followed \#by O (31.5\%) then B (19\%) and the least. prevalence in blood group $\mathrm{AB}(16.4 \%)$. In this study, a high percentage of individuals with blood group 0 (40.9\%) was observed in Class I malocclusion. group, blood group A in Class II malocclusion (35.8) and Class III malocclusion group (30.9\%). This result was in disagreement with Sanjay Prasad 
Gupta ${ }^{(15)}$ who found that a relatively high percentage of individuals with blood group B (32.73\%) was observed in Class I malocclusion group, blood group O in Class II malocclusion group (48.94\%) and Class III malocclusion group (50\%).

Thus, it has always been hypothesized that the presence of a certain kind of pathology may be associated with a specific type of blood group. The statement of Bakare $\boldsymbol{e t}$ al ${ }^{(\mathbf{1 8})}$, seems true that varieties of $\mathrm{ABO}$ may play an important role in immunology and in the prevention of diseases. For definitive establishment of their etiogenic role, multicenter collaborative studies, which include diverse population groups, are required to further explore this relation globally.

\section{CONCLUSION}

The estimation of the correlation between blood groups and malocclusions showed that blood groups have an association with malocclusions with highest prevalence in blood group A followed by O, B and $\mathrm{AB}$ in group of Egyptian population.

\section{REFERENCES}

1. Gheisari R, Ghoreishian M, Movahedian B and Roozbehi A. The association between blood groups and maxillofacial deformities . Indian J Plast Surg 2008; 41:1 38-40.

2. Landsteiner K. Agglutination of normal people blood. Wiener Klinische Wochenschrift (the central European journal of medicine) $1901 ; 14: 1132-4$.

3. Lewis M, Kaita H, Giblett ER and Anderson JE. Genetic linkage analyses of chromosome 9 loci $\mathrm{ABO}$ and AK1. Cytogenet Cell Genet 1978; 22: 452-5.

4. Demir T, Tezel A, Orbak R , Eltas A, Kara C and Kavrut F. The Effect of ABO Blood types on Periodontal Status. Eur J Dent 2007; 1: 139-43.

5. Pinkston JA and Cole P. ABO blood groups and salivary gland tumors (Alabama, United States). Cancer Causes Control 1996; 7: 572-4.

6. Mortazavi H, Hajian S, Fadavi E, Sabour S, Baharvand $\mathrm{M}$ and Bakhtiari S. ABO blood groups in oral cancer: a first case-control study in a defined group of Iranian patients. Asian Pac J Cancer Prev. 2014; 15(3):1415-8.
7. Kaslick RS, Chasens AI, Tuckman MA and Kaufman B. Investigation of periodontosis with periodontitis: Literature survey and findings based on $\mathrm{ABO}$ blood groups. J Periodontol. 1971 ; 42:420-7.

8. Roberts JA. Blood groups and susceptibility to disease: A review. Br J Prev Soc Med 1957; 11:107-25.

9. Koregol AC, Raghavendra M, Nainegali S, Kalburgi N and Varma S. ABO blood groups and Rhesus factor: An exploring link to periodontal diseases. Indian J Dent Res 2010; 21: 364-368.

10. Vivek S, Jain J, Simon SP, Battur H, Supreetha S and Haridas $\mathrm{R}$. Association of $\mathrm{ABO}$ blood group and $\mathrm{Rh}$ factor with periodontal disease in a population of Virajpet , Karnataka: A cross-sectional study. J Int Oral Health 2013; 5:30-4.

11. Charles Louis Schnibben. A Study of the Relationships of the ABO Human Blood Groups, the Rh Factor and Hereditary Malocclusions of the Skeletal Type, Class II, Division 1. Loyola University Chicago 1968.

12. Patrick Michael Flannery. The Abo Human Blood Groups and Skeletal Class III Malocclusions. Loyola University of Chicago 1969,

13. Sharma R, Preethi PN, Nagarathna $C$ and Navin HK. Association of ABO Blood Groups with Malocclusion in Population of Jaipur, India: A Prospective Study. Int J Sci Stud 2015; 2(11): 45-51.

14. Mustafa M. Al-Khatieeb, Sami K Al-Joubori and Shaymaa Shaker Taha. Association of ABO Blood Group and Rhesus Factor with Dental Malocclusion in a Population of Baghdad, Iraq. International Journal of Medical Research \& Health Sciences, 2018, 7(1): 165-169.

15. Sanjay Prasad Gupta. Association of ABO Blood Groups with Occlusal Pattern among Orthodontic Patients of Kathmandu District. EC Dental science 17. 12 (2018): 2119-2129.

16. Shokor FF, Ab Rahaman WS and Alam MK. "Craniofacial morphology with genetic influence of ABO blood Group in malaysian orthodontic patients". International Journal of Pharma and Bio Sciences 6.4 (2015): 412-418.51.

17. Gupta SP . Association of ABO blood groups with occlusal pattern among Orthodontic patients of Kathmandu district. EC dental science 17.12(2018) : 2119- 2129.

18. Bakare AA, Azeez MA and Agbolade JO. Gene frequencies of $\mathrm{ABO}$ and rhesus blood groups and haemoglobin variants in Ogbomoso, South-West Nigeria. Afr J Biotechnol 2006; 5:224-9. 